\title{
INTERACTIONS IN THE MANAGEMENT OF NURSING CARE TO HOSPITALIZED CHILDREN WITH CHRONIC CONDITIONS: SHOWING INTERVENING CONDITIONS
}

\author{
Thiago Privado Silva1, Ítalo Rodolfo Silva², Joséte Luzia Leite ${ }^{3}$
}

\begin{abstract}
${ }^{1}$ Doctoral student at the Programa de Pós-Graduação em Enfermagem, Escola de Enfermagem Anna Nery (EEAN), Universidade Federal do Rio de Janeiro (UFRJ). Rio de Janeiro, Rio de Janeiro, Brazil. E-mail: thiagopsilva87@gmail.com

2 Doctoral student at the Programa de Pós-Graduação em Enfermagem, EEAN/UFRJ. Professor at Universidade Federal do Rio de Janeiro - Macaé campus. Rio de Janeiro, Rio de Janeiro, Brazil. E-mail: enf.italo@hotmail.com

${ }^{3}$ Ph.D. in Nursing. Professor at the Programa de Pós-Graduação em Enfermagem, EEAN/UFRJ. Rio de Janeiro, Rio de Janeiro, Brazil. E-mail: joluzia@gmail.com
\end{abstract}

\begin{abstract}
The study aimed to understand the intervening conditions in the interactions of nurses in managing the nursing care for hospitalized children with chronic conditions. To do that, it used Complex Thinking and Grounded Theory as theoretical and methodological references, respectively. Eighteen subjects participated in the study, pooled into three sample groups: nurses, nursing technicians, and their families. A semi-structured interview was used for data collection. Data analysis followed three stages of coding: open, axial, and selective. The study considered family members, professional experience, the physical structure of the unit, human and material resources, good mood, job satisfaction, confidence, dialogue, and empathy as conditions that influence nurses' interactions in care management. It found that subjective, cognitive, socio-cultural and institutional conditions influence the interactions of nurses, creating order/disorder in nursing care management.
\end{abstract}

DESCRIPTORS: Pediatric nursing. Management. Chronic disease. Interpersonal relations.

\section{INTERAÇÕES NO GERENCIAMENTO DO CUIDADO DE ENFERMAGEM À CRIANÇA HOSPITALIZADA EM CONDIÇÃO CRÔNICA: REVELANDO CONDIÇÕES INTERVENIENTES}

RESUMO: O estudo objetivou compreender as condições intervenientes às interações do enfermeiro no gerenciamento do cuidado de enfermagem à criança hospitalizada em condição crônica. Para tanto, foram utilizados como referenciais teórico e metodológico, respectivamente, o Pensamento Complexo e a Grounded Theory. Participaram do estudo 18 sujeitos, organizados em três grupos amostrais: enfermeiros, técnicos de enfermagem e familiares. A entrevista semiestruturada foi utilizada para coleta de dados. A análise dos dados seguiu as três etapas de codificação aberta, axial e seletiva. Compreendeu-se que o familiar, a experiência profissional, a estrutura física da unidade, os recursos humanos e materiais, o bom humor, a realização profissional, a confiança, o diálogo e a empatia são condições que influenciam as interações do enfermeiro no gerenciamento do cuidado. Concluiu-se que condições de âmbito subjetivo, cognitivo, sociocultural e institucional influenciam as interações do enfermeiro, gerando ordem/desordem no gerenciamento do cuidado de enfermagem.

DESCRITORES: Enfermagem pediátrica. Gerência. Doença crônica. Relações interpessoais.

\section{INTERACCIONES EN LÁ GESTIÓN DE ATENCIÓN DE ENFERMERÍA A NIÑOS HOSPITALIZADOS CON CONDICIÓN CRÓNICA: REVELANDO CONDICIONES QUE INTERVIENEN}

RESUMEN: El estudio tuvo como objetivo comprender las condiciones que intervienen en las interacciones del enfermero en la gestión del cuidado de enfermería para los niños hospitalizados con enfermedades crónicas. Fueron utilizados como referência teórica y metodológica, respectivamente, el Pensamiento Complejo y la Grounded Theory. Han participado del estudio 18 sujetos organizados en tres grupos de muestra: enfermeros, técnicos de enfermería y familiares. La entrevista semi-estructurada fue usada para la recolección de los datos. El análisis siguió las tres etapas de codificación: abierta, axial y selectiva. Se entiende que la familia, la experiencia laboral, la estructura física de la unidad, los recursos humanos y materiales, el buen humor, la satisfacción laboral, la confianza, el diálogo y la empatía son las condiciones que influyen en las interacciones de las enfermeras en la gestión del cuidado. Se concluye que condiciones de ambito subjetivo, cognitivo, socio-cultural e institucional influyen lãs interacciones del enfermero generando orden/desorden en la gestión del cuidado de enfermería. DESCRIPTORES: Enfermería pediátrica. Gerencia. Enfermedad crónica. Relaciones interpersonales. 


\section{INTRODUCTION}

With regard to the management of nursing care delivered to hospitalized children with chronic conditions, nurses establish multiple interactions to meet the children's and their family members' needs. There is a network of occurrences, actions, interactions, retroactions, determinations, and opportunities $^{1}$ that characterize the development of this practice as a complex phenomenon.

To properly perform their managerial duties, nurses must establish links that facilitate close relations between subjects, culminating in mutual interactive processes that value dialogue and contact. ${ }^{2}$ Interaction emerges as the first experience towards managing nursing care to hospitalized children with chronic conditions and, in this way, is a condition that assists nurses in the identification of children's and family members' needs, enabling the planning of care.

However, weak interactions in and between teams, in addition to fragmented working processes, have hindered health production in the context of the Brazilian Unified Health System (SUS). ${ }^{3}$ Moreover, the literature points out weaknesses in the interaction between nurses and family members, as well as between the nurse and the medical team in the context of the management of care delivered to hospitalized child with chronic conditions. ${ }^{4}$ This reality could restrict the establishment of solidarity links, networking, and collective participation in the SUS care and management processes. ${ }^{3}$

As such, interaction is understood as a heterogeneous process taking place in co-existential contexts where movements that cooperate with either convergence or divergence of social actors in a relational process are produced and reproduced. ${ }^{5}$ This affirmation shows the existence of intervening conditions capable of favoring or restricting nurses' interactions in nursing care management, characterizing this practice as dynamic and procedural.

In this way, intervening conditions are resourcing units that generate order and disorder in nurses' interactions in their practices of care. In light of the complexity, order refers to repetitions, invariants, and the steadiness of the relational process, while disorder refers to disorganization, disintegration, errors, and uncertainties. ${ }^{1}$ These dimensions are complementary to the dynamic development of relational processes because these constitute the dialogic of social interactions.

This raises the following questions: Which conditions are considered to intervene in nurses' interactions when managing nursing care to hospitalized children with chronic conditions? How do these conditions influence nurses' interactions? In this way, this study was intended to understand the conditions that intervene in nurses' interactions in the management of nursing care to hospitalized children with chronic conditions in the light of complexity.

\section{METHOD}

This study used a qualitative approach, having Grounded Theory (GT) as methodological framework, and Edgar Morin's Complex Thinking as theoretical framework.

Grounded Theory is a widely used research method in the field of nursing because of its contributions toward understanding little-explored phenomena and producing explanatory models and theories. ${ }^{6}$ Complex Thinking, in turn, is a theoretical perspective focused on the capture and understanding of the complementarity and interdependence between different components that make up human complexity to establish its coordination, integration, and interpretation. ${ }^{1}$ Because of this, understanding the study object based on this theoretical framework means considering nursing care management as a complex social practice where interaction is a condition that promotes care.

Data were collected at the Pediatric Hospitalization Unit (UIP) of a federal university hospital in the city of Rio de Janeiro, Brazil, from July to November 2012. This hospital provides pediatric health care, and more than $50 \%$ of the children hospitalized there have chronic or rare diseases, or are hospitalized without a clear diagnosis. ${ }^{7}$ The UIP is composed of six nursing wards with six to eight beds each. The nursing team ${ }^{*}$ is composed of 62 nursing technicians and 16 nurses. Five nurses work on the morning shift, of which there are three day laborers and two nurses on duty, with two nursing technicians per nursing ward, on average. On day and night shifts, such as during weekends and holidays, there are two nurses on duty and one nursing technician per nursing ward.

In Brazil, nursing is divided into three categories: nurse, nursing technicians and nursing auxiliaries, being the highest level is a nurse, followed by technicians and auxiliaries. Translator's note. 
Data were collected using semi-structured interview. The study participants were defined based on the theoretical sample. ${ }^{7}$ Considering that the nurse is the professional responsible for all nursing services, including care management, these professionals were interviewed first. The following were the inclusion criteria: at least three years of experience with care to children with chronic conditions; assigned to the UIP; and one year of labor linked with the institution. The sample excluded nurses on vacation, authorized license, and on leave. The following question has guided the interview with nurses: "Based on your perception, can you tell me which factors influence your interactions when managing care to children with chronic conditions?" Eight nurses participated in the first sample group, of whom seven were women and six men, with between four and 32 years of experience in providing care to children with chronic conditions.

Analyses of the interviews with the nurses showed that the management of nursing care to hospitalized children is developed based on the interactions established by nurses with nursing technicians. This indication directed the investigation toward nursing technicians in order to get to know their perceptions about intervening factors related to the practice of care. The inclusion and exclusion criteria for this group were the same as those employed to assemble the first sample group. The question that directed the interviews with nursing technicians was as follows: "Based on your perception, can you tell me which factors influence your interactions when managing care to children with chronic conditions?" This second sample group was composed of six nursing technicians, all women, with between five and 27 years of experience in providing care to children with chronic conditions.

Treatment of the analytical data showed that family members of children with chronic conditions influence the development of care. In this way, the investigation focused on family members to become acquainted with their perceptions about their interactions with the nursing team with regard to the management of care to their children. Following was the inclusion criterion: be a family member of a child hospitalized at the UIP and with a chronic condition. Interviews with family members started with the following question: "In your view, which factors hinder or facilitate your interaction with the nursing team?" The third sample group was composed of four family members, all mothers of children with chronic conditions.
It is worth mentioning that the conclusion of data collection was determined by theoretical saturation, where new data collected no longer changed the concepts built in relation to their theoretical consistency and density. ${ }^{8}$ In Grounded Theory, data are collected and analyzed following the stages of open, axial, and selective coding.

In open coding, data were coded line by line, generating preliminary data that, in turn, after being pooled according to sense similitude, gave rise to conceptual codes. Conceptual codes were compared with one another and organized by similitude, giving rise to categories and subcategories. In axial coding, categories were related one to another and with their subcategory in order to define their properties and dimensions. At this point an analytical tool named Paradigm was employed to allow the gathering/ordering/integration of previously elaborated categories, favoring the emergence of the study's core phenomenon during the selective coding stage. In addition to the coding process, memoranda and diagrams were prepared to assist theoretical data analysis. ${ }^{8}$

The category "Showing the conditions intervening in interactions in management of nursing care" arose from the data analysis as an intervening condition of the core phenomenon "Establishing relationships and interactions to manage nursing care to children hospitalized in the Pediatric Hospitalization Unit and with [a] chronic condition." It is relevant to show the circumstances that influence nurses' interactions in the management of nursing care and thus it is presented separately herein.

In compliance with Resolution 466/12 issued by the National Health Council, data collection started after the study had been approved by the Committee of Ethics in Research of the Escola de Enfermagem Anna Nery (EEAN/HESFA/UFRJ), report \#8921, and by the Committee of Ethics in Research of the University Hospital where the study was carried out, report \#07/12. The study subjects were asked to sign the Free and Informed Consent Form. To ensure anonymity, nurses' speeches were identified with the letter E; nursing technicians' speeches with $\mathrm{T}$, and the family members' speeches with F. All are followed by a number referring to the order of interviews in each sample group (for example: E1, T1, F1).

\section{RESULTS}

The category "Showing the conditions intervening in interactions in management of nursing 
care" is composed of the following subcategories: Referring to conditions that intervene in interactions with children; Listing intervening conditions that facilitate and limit interactions with family members; and, Presenting conditions that intervene in teamwork.

The subcategory "Referring to conditions that intervene in interactions with children" shows the conditions that influence nurses' interactions when managing care to hospitalized children with chronic conditions. In this regard, the speech of nurse E3 shows that the dynamic of on-duty services, comparable to the number of nursing professionals, are intervening conditions for interactive processes.

If I am by myself with the child during my supervision time, this interaction is harder [...] it is the shift pace and the work structure that will enable stronger or weaker interaction with the child (E3).

In addition, the child's family member also influences the care relations established between the nurse and the child, as shown in the following speeches:

If [the] parents don't like you, the child won't like you (T3).

When the family is troublesome, it's hard; you have to deal with the mother's setback (T5).

Nurses expressed difficulties in dealing with the shortage of nursing professionals and materials, added to the high number of hospitalized children.

Our staff is not enough; in some nursing wards we don't have even two professionals to serve these children (E8).

Sometimes you have to do a procedure and some material is missing; many times materials are of bad quality (E5).

I guess the number of children in nursing wards. Sometimes we can't pay attention to everyone [...] this hinders interaction (E2).

The following speech shows how these conditions influence a nurse's interactions in the care to children with chronic conditions.

You shorten the time for explaining, participating in the direct care to the child [...] with the demand we have from chronic patients, that is hard, is more distressing, and we get more tired, quality diminishes (E7).

On the other hand, the physical structure of the unit, the length of experience in providing care to children with chronic conditions, good mood, and professional fulfillment were mentioned by nurses as conditions that facilitate the relations of care.
The physical layout of the unit really facilitates [...] here you have a broad view of everything, have easy access to nursing wards (E3).

Your length of work, experience, helps you to handle hardships [...] I love children and feel good about life, and it facilitates (E7).

What really helps is that I am professionally fulfilled (E4).

Family members reinforced that good mood, and professional satisfaction with the job facilitated the relations of care with the child.

I think that loving the profession facilitates their interaction with us (F1).

I guess it is the good mood; when the person comes to work with a good mood and works with something they love, in my view, [that] is the most facilitating factor (F2).

Listing intervening conditions that facilitate and limit interactions with the family member is the subcategory that presents the circumstances that modify nurses' interactions with the family member of the hospitalized child with a chronic condition. In this light, work overload, institutional aspects, and the socio-cultural conditions of the children's family members are perceived by nurses as intervening factors in this relationship. Below are some excerpts of speeches that illustrate this situation.

The factor that influences the most is work overload; I end up doing everything faster, and I know I could pay more attention to the chronic patient's mother (E5).

In this institution there is huge difficulty regarding rules, regulations oriented to companions [...] there is no name tag, cloth, activities to companions (E3).

I think the cultural and educational level is hard and makes a difference [...] I think the socio-cultural level, education level, it hinders a lot because you can hardly convince someone about the importance of washing hands, many times they [family members] don't understand it (E7).

The cultural issue influences the relation with family members (T4).

On the other hand, talking, trusting, and having empathy were considered to be facilitating factors in care relations with the family member.

I believe that when we come and explain what is going to be done, talk [...] (E5).

I think when I understand their difficulties, when I put myself in their shoes, understand their difficulties, I can be tolerant (E8).

In my view, trust facilitates. I try to treat parents with respect $(\mathrm{T} 1)$. 
In line with the aforementioned, the following speech by a family member reinforces trust as a condition that facilitates interactive processes with the nursing team.

Trust helps a lot, because just like I trust them, they also trust me. I think that trust, respect, and affection are the ground of everything, and we have it one with the other (F4).

The subcategory "Presenting conditions that intervene in teamwork" shows the conditions considered to intervene in nurses' interactions with the multi-professional health team in their working process. In this light it is worth mentioning that nurses, in their working context, do not work in isolation, but with the nursing team's professionals and professionals of other teams such as, for example, the medical team. As regards their relationship with the medical team's professionals, nurses listed some difficulties, as shown in the following speeches:

What makes things hard is the nursing knowledge with the medical knowledge (E1).

What could cause difficulties with the medical team, sometimes, are recently graduated physicians that come [in] thinking they know everything; they feel better than us (E5).

In some situations the physician does not value what we, the nursing team, say about the patient, and it encumbers, and patient suffers (E6).

These circumstances influence nursing care to hospitalized children with chronic conditions, as shown in the professional example below.

For example, in some situations, depending on the peripheral vein network of the child, I recommend deep access, even a PICC, and the physician says it is not necessary. When the physician finally considers the PICC, the child is all punctured and the PICC is no longer possible. All that makes things harder. A professional leaves it to the other and delays medications like antibiotics, and the child suffers even more. I believe this barrier hinders things. Nursing knowledge should be appraised (E1).

Regarding the conditions considered to be facilitators during their interactions with medical teams, nurses referred to knowledge and professional experience.

I believe knowledge and practical experience, because length of experience makes you more acceptable, speak with more confidence (E1).

At some moments the nursing team presented relational disorders. In this context, personnel management, when not properly conducted, is a factor that could generate conflict, as stated by the following nurse:
Short staffentails redeployment issues. Sometimes it happens with some professionals. They argue 'Why this?' 'Why that?' (E8).

In this sense, the nursing technician reaffirms that personnel management, if not properly done, can lead to relational conflicts within the team.

When sharing personnel, some nurses attach priority to people that complain more rather than to [those who are] overloaded (T3).

The lack of day laborer nurses in the unit was mentioned as a factor that damages interaction in teamwork.

The problem is that there is only one nurse to cope with a lot of things, many children for few nurses (T6).

On the other hand, communication, respect for others, and leadership were mentioned as factors that facilitate nurses' relationships in teamwork.

With the team we are always trying to be leaders in supervision, but with friendship, respect. I guess it facilitates (E5).

Things get harder without communication; communication facilitates things (T2).

The difficulties and facilities referred to regarding teamwork point out the importance of appraising the complexity of the health work context, because thinking about teamwork implies considering inter-professional relationships and the factors that may influence these.

\section{DISCUSSION}

Based on the results presented, we found that there is a wide range of factors that are conditional to the nurses' interaction network in managing nursing care to hospitalized children with chronic conditions, which can either facilitate or limit the relational and interactive processes.

Results showed that the dynamics of on-duty services and the number of nursing professionals can influence nurses' interactions, either favoring or hindering their relationship with the child. This way, it is assumed that context-related aspects can condition care management, because these demand consistent self-organization from the nurse to handle eventual disorder in their working context.

Self-organization has to do with the concept of self-production, recalling a core principle of Complex Thinking, namely that of recursion. This principle breaks with linear causality, considering the nonlinearity of complex reality where the cause acts on the effect, and the effect retroacts on the cause. ${ }^{9}$ 
It was also found that the family dimension has an important influence on the interaction established between nurses and children. In this regard, the literature ${ }^{10}$ registers that parents influence the wellbeing of the child with chronic disease, and play an important role in the process of adapting the child to his/her new condition. It is worth mentioning that the nursing team should view the family member as a facilitating agent in the process of care to the hospitalized child ${ }^{11}$ and, in this way, also deserves care. In this way, nurses should be ready to approach and evaluate the family member's needs, including those related to coping with and becoming adjusted to the reality imposed by the child's disease. ${ }^{12}$

Professionals approached in the study said that they deal with plural situations of disorder when managing nursing care. In this study, disorder was related to the shortage of human resources in nursing and the low quantity and quality of material resources associated with the high number of children hospitalized with chronic conditions that demand permanent care by the team. These are conditions that change nursing services' quality and challenge professionals who provide safe care to hospitalized children.

The shortage of human resources in nursing, added to the high number of hospitalized children, has generally led nursing professionals to work overload. This situation damages their interactions, because the professional shortens the time devoted to each child's care and, in this way, is poorly involved in direct care. Moreover, this situation generates fatigue and stress that impact the efficiency of the care provided to the child.

Based on the aforementioned, in light of Complex Thinking, personnel management in nursing work is a dynamic phenomenon that can be made clear based on the principle of unitas-multiplex, ${ }^{1}$ where interaction between the parties may inhibit or maximize qualities in the organization as a whole. Results have also shown that, in the management of nursing care to hospitalized children with chronic conditions, networking can be affected by the work overload of these professionals. This work overload is a condition that limits interactive processes, mainly among nurses, because it influences delivery of care, unit management, and the team as a whole. ${ }^{13}$

On the other hand, participants reported that the unit's physical structure, practical experience with care to children, good mood, and professional fulfillment are conditions that facilitate nurses' interactions in care management. The last two factors were also referred to by family members. As regards the unit's physical structure, one study ${ }^{12}$ observed that nurses' working processes are implemented in different ways, depending on the scenario wherein the nurse is inserted, emphasizing that nurses' work and their interactions are conditioned by the organizational and structural conditions of the unit where these professionals are inserted.

In this way, the inseparability between the phenomenon and its context should be evaluated, seeking a globalizing and complex thinking. ${ }^{1}$ Context is required to make care relations advance, because knowledge develops not so much through formalization and sophistication but, above all, through the capacity of contextualizing and encompassing. ${ }^{9}$

As regards experience and good mood-based practice, a study ${ }^{14}$ carried out with family members of patients in palliative oncologic care showed that these circumstances are perceived as important in their relationships with the nursing team and, in this way, should be apprised by the team in interpersonal relations. In addition, a study ${ }^{15}$ carried out with children undergoing cancer treatment showed that they appreciated when information and explanations provided by nurses were combined with a good mood.

As regards professional fulfillment, the literature $^{16}$ registers that it seems to be related to a feeling of satisfaction with health work, understood as an affective reaction of employees to their work, based on the comparison between actual and intended results. It is influenced by extrinsic factors such as salary and working conditions, as well as by intrinsic factors such as opportunity for professional and personal development as well as appreciation. It is a condition that favors motivation and professional productivity, fostering high quality care to patients. ${ }^{16}$

Interpersonal relationship standards vary according to different patterns such as culture, age, gender, education, socio-economic conditions, and religion. ${ }^{17}$ In this sense, this study found that family's socio-cultural level influences interactions with nurses, demanding from this last group a language suitable to the family's socio-cultural standard so that they can understand the importance of the guidance provided, avoiding potential disorder in the care context.

In light of Complexity Theory, culture corresponds to the first human capital, because it is the social heritage of human beings. It is composed of the set of usages, customs, values, strategies, beliefs, 
and practices that are eternalized from generation to generation, being reproduced in each individual, generating and regenerating social complexity. Cultures feed social identities in their more specific aspects and, as such, a culture may be difficult to comprehend from the point of view of another culture. $^{9}$

Nurses consider empathy, trust, and talking with the child's family members as attitudes that facilitate their interactive process. In another study, ${ }^{18}$ nurses perceived these factors as strategies of interaction with clients in oncologic-hematological units, and they were employed to ease their clients' suffering. As regards trust, it is worth mentioning that it should be part of care relationships as a basic social process for efficacious working relations between nurses and the hospitalized child's family. ${ }^{19}$ As such, empathy allied to trust is an important tool in the interactive process, because it favors the exercise of sensitivity in care relations. ${ }^{2}$

Empathy is related to the individual's capacity for understanding and not judging the other's positive and negative experiences. ${ }^{17}$ It evokes the notions of intersubjectivity, affectivity, and understanding. The possibility of understanding the other as a singular individual emerges from intersubjectivity where connivance is produced. Connivance is expressed in affectivity that allows for warm communication in interpersonal relations. Identification with the other allows understanding, ${ }^{10}$ which is the ground for empathy. In this way, it is an important strategy of interaction in care relationships.

Allied to this perspective, talking with the child's family member can also be a condition that facilitates care relationships, as shown in this study. Talking with family members allows for clarifying doubts, providing guidance and information on the child's health, and explaining the importance of and need for the procedures to which the child will be subjected. In this regard, it is worth mentioning that lack of clear and accurate information is one of the most concerning factors, and causes anxiety among the parents of hospitalized children. ${ }^{11}$ It is a circumstance that can generate unfavorable behaviors in family members regarding care relationships, restricting their interaction with nurses and the team as a whole.

In multidisciplinary health teamwork, nurses show the existence of situations of conflict with the medical team resulting from hierarchical disputes over authority, power, and knowledge. ${ }^{20}$ It is a conflict between complementarity, expansion of autonomy, and rivalry between professionals in cases of care to children and, in this way, a tension resulting from the shock between the complementarity and interdependence of professionals in relationships of care. ${ }^{21}$

On the other hand, the results of this study show that the interactions between nurses and the medical team are facilitated when nurses possess scientific knowledge and accumulated experience in their practice of care to hospitalized children with chronic conditions. In line with this result, a study ${ }^{22}$ showed that the experience accumulated during professional exercise and, above all, through managerial practice, allows nurses to perform managerial tasks with confidence, enabling them to take on the responsibilities inherent to their duties, make decisions, and have better relationships in teamwork.

Relational conflicts also take place within the nursing teamwork. Despite that, improper human resources management in nursing can be a factor that generates stress and conflict in teamwork. Moreover, the lack of day laborer nurses was also mentioned by the participants as a condition that damages teamwork. These aspects cause us to think about the complexity of teamwork, where order, disorder, organization, unit, diversity, and complementarity ${ }^{1}$ are perceived as elements that lead the interaction network. On the other hand, communication, respect for the other, and leadership were considered to be conditions that facilitate teamwork.

Communication in administrative processes and working relations is crucial to exchange information, ideas, orders, and facts because it favors coordinated actions, reduces differences, and brings people together on behalf of shared objectives. ${ }^{23} \mathrm{~A}$ study ${ }^{24}$ adds that skills related to communication, work coordination, and interprofessional relationships are crucial to improving care processes managed by nurses. In this logic, communication skill is also required to develop leadership focused not only on managerial duties, but present in all contexts and activities of nurses, ${ }^{25}$ because the literature consistently refers to it in association with the idea of changing health services. ${ }^{26}$

\section{CONCLUSION}

The results of this study emerged from the relational experiences of nurses, nursing technicians, and family members regarding the management of care provided to hospitalized child with chronic conditions. It found that nurses' interactions in managing nursing care to children with chronic conditions are influenced by conditions at subjec- 
tive, cognitive, socio-cultural, and institutional levels that promote order, disorder, interaction, and organization of relations of care to children. Here, disorder refer to work overload, a shortage of nursing professionals, low quantity and quality of material resources in the unit, and hierarchical disputes in teamwork. These are conditions that limit nurses' interactions in nursing care.

On the other hand, communication, empathy, trust, leadership, professional fulfillment, and knowledge accumulated through experience emerged from our results as conditions that facilitate care relations. As such, the study points out the nurse's need to develop relational, cognitive, subjective, personal, and ethical competencies in the management of nursing care to hospitalized children with chronic conditions.

Finally, this study suggests the need for investigations that give voice to the medical team taking care of the child with chronic conditions because, as presented in these results, these professionals lead the practice of nursing care management, sometimes working as collaborators and, at other moments, as generators of tensions in care relationships. This circumstance will allow for a better-contextualized understanding of the study subject presented herein.

\section{REFERENCES}

1. Morin E. Introdução ao Pensamento Complexo. $5^{\mathrm{a}}$ ed. Lisboa (PT): Instituto Piaget; 2008.

2. Lanzoni GMM, Lessman JC, Sousa FGM, Erdmann $\mathrm{AL}$, Meirelles BHS. Interações no ambiente de cuidado: explorando publicações de enfermagem. Rev Bras Enferm. 2011; 64(3):580-6.

3. Ministério da Saúde (BR). Secretaria de Atenção à Saúde. Núcleo Técnico da Política nacional de Humanização. Humaniza SUS: Documento base para gestores e trabalhadores do SUS. $4^{\mathrm{a}}$ ed. Brasília (DF): Editora do Ministério da Saúde, 2008.

4. Silva TP, Silva MM, Valadares GC, Silva IR, Leite JL. Nursing care management for children hospitalized with chronic conditions. Rev Bras Enferm. 2015; 68(4):6418.

5. Erdmann AL, Mello ALSF, Andrade SR, Koerich MS, Klock P, Nascimento KC. Sistemas de cuidado em enfermagem e saúde: as interações vivenciadas nos grupos de pesquisa. Cienc Cuid Saúde. 2009; 8(4):675-82.

6. Leite JL, Silva LJ, Oliveira RMP, Stipp MAC. Thoughts regarding researchers utilizing Grounded Theory. Rev Esc Enferm USP. 2012; 46(3):772-7.

7. Sousa TV, Oliveira ICS. Interação familiar/ acompanhante e equipe de enfermagem no cuidado à criança hospitalizada: perspectivas para enfermagem pediátrica. Esc Anna Nery Rev Enferm. 2010; 14(3):551-9.

8. Strauss AL, Corbin J. Pesquisa Qualitativa: técnicas e procedimentos para o desenvolvimento da teoria fundamentada. Porto Alegre: Artmed; 2008.

9. Morin E. O método 5: a humanidade da humanidade. $5^{\mathrm{a}}$ ed. Porto Alegre (RS): Sulina; 2012.

10. Eccleston C, Palermo TM, Fisher E, Law E. Psychological interventions for parents of children and adolescents with chronic illness. The Cochrane Database Syst Rev. 2012;15(8):CD009660.

11. Lima AS, Silva VKBA, Collet N, Reichert APS, Oliveira BRG. Relações estabelecidas pelas enfermeiras com a família durante a hospitalização infantil. Texto Contexto Enferm. 2010; 19(4):700-8.

12. Popp JM, Conway M, Pantaleao A. Parents' experience with their child's cancer diagnosis: do hopefulness, family functioning, and perceptions of care matter? J Pediatr Oncol Nurs. 2015; 32(4):253-60.

13. Giordani JN, Bisogno SBC, Silva LAA. Percepção dos enfermeiros frente às atividades gerenciais na assistência ao usuário. Acta Paul Enferm. 2012; 25(4):511-6.

14. Silva MM, Moreira MC, Leite JL, Erdmann AL. Análise do cuidado de enfermagem e da participação dos familiares na atenção paliativa oncológica. Texto Contexto Enferm. 2012; 21(3):658-66.

15. Angstrom-Brannstrom C, Norberg A. Children undergoing cancer treatment describe their experiences of comfort in interviews and drawings. J Pediatr Oncol Nurs. 2014;31(3):135-146.

16. Klopper HC, Coetzee SK, Pretorius R, Bester P. Practice environment, job satisfaction and burnout of critical care nurses in South Africa. J Nurs Manag 2012;20(5):685-95.

17. Formozo GA, Oliveira DC, Costa TL, Gomes AMT. As relações interpessoais no cuidado em saúde: uma aproximação ao problema. Rev Enferm UERJ. 2012; 20(1):124-7.

18. Costa VGS, Rodrigues BMRD, Pacheco STA. As relações interpessoais no cuidar do cliente em espaço onco-hematológico: uma contribuição do enfermeiro. Rev Enferm UERJ. 2012; 20(2):209-14.

19. Hall J, Nayar S. Building trust to work with children after a severe traumatic accident. Contemp Nurse. 2013; 46(2):161-9.

20. Vaghetti HH, Padilha MICS, Filho WDL, Lunardi VL, Costa CFS. Significados das hierarquias no trabalho em hospitais públicos brasileiros a partir de estudos empíricos. Acta Paul Enferm. 2011; 24(1):87-93.

21. Sousa FGM, Erdmann AL, Mochel EG. Condições limitadoras para a integralidade do cuidado à criança na atenção básica de saúde. Texto Contexto Enferm. 2011; 20(esp.):263-71.

22. Santos JLG, Prochnow AG, Silva DC, Silva RM, Leite JL, Erdmann AL. Prazer e sofrimento no exercício 
gerencial do enfermeiro no contexto hospitalar. Esc Anna Nery Enferm. 2013; 17(1):97-103.

23. Santos JLG, Procnow AG, Lima SBS, Leite JL, Erdmann AL. Comunication conceptions in hospital nursing management between head nurses in a university hospital. Rev Esc Enferm USP. 2011;45(4):959-65.

24. Onishi M, Kanda K. Expected roles and utilization of specialist nurses in Japan: the nurse administrators' perspective. J Nurs Manag. 2010; 18(3):311-8.

25. Curtis EA, Vries J, Sheerin F. Developing leadership in nursing: exploring core factors. Br J Nurs. 2011; 20(5):306-9.

26. Simons J. A proposed model of the effective management of children's pain. Pain Manag Nurs. 2015; 16(4):570-8. 